\title{
Ordinal Or Cardinal Utility: A Note
}

Walter E. Block

Harold E. Wirth Eminent Scholar Endowed Chair and Professor of Economics

Joseph A. Butt, S.J. College of Business Loyola University New Orleans, U.S.A.

e-mail:wblock@loyno.edu

Robert Wutscher

Independent Scholar

3 Warblers Close

Constantia 7806

South Africa

e-mail: rwutscher@telkomsa.net

\begin{abstract}
:
Modern microeconomic theory is based on a foundation of ordinal preference relations. Good textbooks stress that cardinal utility functions are artificial constructions of convenience, and that economics does not attribute any meaning to "utils." However, we argue that despite this official position, in practice mainstream economists rely on techniques that assume the validity of cardinal utility. Doing so has turned mainstream economic theorizing into an exercise of reductionism of objects down to the preferences of 'ideal type' subjects.
\end{abstract}

Keywords: Ordinal, cardinal, utility

We thank William Barnett II and Robert P. Murphy for suggestions which greatly improved our paper. All remaining errors and infelicities are of course our own responsibility.

\section{Introduction}

This paper will attempt to demonstrate that the ordinal utility of Austrian economics is the only version of this concept compatible with human action [42]. It is our contention that although mainstream or neoclassical economists do utilize ordinal utility, they do so only superficially. More basically, they cleave to cardinal utility, which, we maintain, is incompatible with a proper analysis of utility. In section II we discuss these two very different understandings of utility. Section III is devoted to an analysis of a case in point, wealth redistribution. The purpose of section IV is to deal with indifference curves: we utilize them to defend ordinal utility and disparage the cardinal variety. The focus is on subjectivism in section V. We conclude in section VI. 


\section{Ordinal and Cardinal Utility}

Ordinal utility may be defined as ranking, and/or setting aside in human action, or choice. Etymologically, ordinality in this context stems from ordering, preferring. For example, here might be the rank ordering of Mrs. Smith, consumer: 1st: 10 eggs; 2nd: \$5; 3rd: 9 eggs; 4th: \$4; 5th: 8 eggs; 6th: $\$ 3 . .1$

There is no dispute about this amongst economists. In Hicks' [31] seminal discussion of Pareto, the old utilitarian notions were thrown overboard. No longer did mathematical economists need to rely on dubious assumptions that troubled philosophers; the Law of Demand and other components of consumer theory could be reformulated with a purely ordinal foundation. There are no extant cases where a member of the dismal science in good standing rejected this concept, or denied that we are capable of such orderings $[54$, p. 6]. Ordinal utility, then, is one of the pillars of the modern dismal science.

Cardinal utility, in very sharp contrast, is a different matter indeed. Here, numerical measures of utility are assigned to different goods, services, objects. For example, one might say that for Mr. Jones, a pencil offers him 5 utils (units of happiness or utility), a wrist watch 10 utils, and a shirt, 20 utils. Since these are all cardinal, or objective numbers, it is thus possible to perform mathematical operations on them. For instance, based on these cardinal numbers, we are entitled to infer that for Jones, a shirt is equivalent, in terms of utility, to two watches, or to four pencils; that two pencils are worth, to him, one watch. ${ }^{2}$

Very few economists accept cardinal utility, at least the rather simplistic or elemental version of it we have so far discussed. They full well realize that, while there are indeed objective measures of length (inches, meters, miles), weight (pounds, kilograms), speed (miles per hour), etc., there are no such objective measures of happiness or utility, such as utils. These are merely a heuristic device, so to speak, for most professionals in the discipline. ${ }^{3}$

\section{Wealth Redistribution}

There are of course exceptions. For example, one of the justifications for income redistribution from rich to poor can be seen in diagram \#1. Here, utility appears explicitly in the form of "utils," on the $y$ axis, while money, or wealth, is depicted on the $x$ axis. The downward sloping curve illustrates decreasing marginal utility, from which we can deduce that a dollar taken away from the rich person, $B$, and given to the poor person, $A$, will increase total utility, in that the last dollar spent by $B$ yields him less satisfaction than the marginal dollar spent by $A$.

According to Pigou [46, p. 89]: “...it is evident that any transference of wealth from a relatively rich man to a relatively poor man of similar temperament, since it enables more intense wants to be satisfied at the expense of less intense wants, must increase the aggregate sum of satisfaction." ${ }^{, 4}$ If this is not the employment of cardinal utility in the context of technical economics, it is difficult to know what would be.

This treatment is highly problematic in that not only does it embrace explicit cardinal utility, it also engages in interpersonal comparisons of utility. It is one thing to claim that Jones values his shirt twice as highly as his watch; it is quite another, and even more fallacious if possible, to take the position that Jones derives half as much satisfaction from his pencil as does Smith from her egg.

Nor is this wealth redistribution argument the only case on record where cardinal utility is embraced so explicitly. ${ }^{5}$ But these are few and far between, and thus less harmful to our profession; they are not endemic. 


\section{Indifference Curves}

The same cannot be said, unfortunately, for indifference curve analysis. This practice is so ubiquitous that no citation is even offered. How, then, do indifference curves logically imply cardinal utility?

At first glance, this is not the case. Far from it. In diagram \#2 we depict the "usual" indifference curve set. Note that the three indifference curves are labeled 5, 6, and 7 utils, respectively, in increasing order as we move away from the origin. The argument for the interpretation of this graph in terms of ordinal, not cardinal utility is the following: the numbers, 5, 6 and 7 serve, merely, as markers, in this context. And, as such, they are clearly ordinal not cardinal. For example, we could have labeled the three indifference curves, instead, 50, 60 and 70 utils, or 500, 600 and 700 utils, or, for that matter, 1, 2 and 3 utils, or 10, 20 and 30 utils, and it would not have made any nonevermind. All that any of the labels would have indicated is that the indifference curve closest to the origin yields the least utility, the one furthest away, the most, and the one in the middle takes on an intermediate role in this regard. "If that isn't ordinal utility, what is?" might argue the advocate of interpreting indifference curves solely as ordinal.

This argument however, moves too fast. This can be seen by focusing on point $C$, where the budget line and indifference curve " 6 " are tangent to one another. The algebraic interpretation of this joinder is of course:

$$
\frac{\mathrm{MUy}}{\mathrm{MUx}}=\frac{\mathrm{P} y}{\mathrm{P} x}
$$

There is no problem with the right side of this equation. The prices of $Y$ and $X$, respectively, are properly cardinal numbers, and the usual mathematical operations (division in this case) may be performed on them. Matters are far more difficult with the left side of this equation. For, here, we are dividing one number by another number, and, this can only be done with regard to cardinal numbers, not ordinal ones. For example, it is mathematically correct ${ }^{6}$ to divide the cardinal number 100 by the cardinal number 50 and arrive at the cardinal number 2 . But, what are we to say of an attempt to divide the ordinal number $100^{\text {th }}$, by the ordinal number $50^{\text {th }}$, and derive the ordinal number $2^{\text {nd }}$ ? This would be an utter impossibility. Indeed, it would be mathematical gibberish.

Nor will there be any improvement in such matters merely by transposing equation (1) into (2):

(2)

$$
\frac{\mathrm{MUy}}{\mathrm{P} y}=\frac{\mathrm{MU} x}{\mathrm{P} x}
$$

If anything, there is now a worsening. For in equation (1), at least the right side of it achieves mathematical legitimacy. Not so in equation (2). For, it is illicit to divide an ordinal number by a cardinal one. For example, the mathematical phrase, " $18^{\text {th }}$ divided by 3 " succeeds in yielding only a literally meaningless statement. It is certainly not true that " $18^{\text {th }}$ divided by 3 " is equal to the cardinal number 6 , nor, yet, to the ordinal number $6^{\text {th }}$. On the contrary, it is quite literally meaningless. ${ }^{7}$

Thus, we can see that the mere labeling of the indifference curves masks the underlying reality. Yes, the nomenclature utilized in marking them appears, superficially compatible with ordinal utility. After all, if 5, 6 and 7 serve, merely, as markers, and could be substituted for by 50,60 and 70 utils, or 500, 600 and 700 utils, or, 1, 2 and 3 utils, or 10, 20 and 30 utils, then this is all compatible with ordinality. However, this is not so; indeed, cannot be correct. For, given what the tangency point tells 
us, there are and must of necessity be cardinal numbers involved in this technique. How else could the mathematical operations performed on them in equations 1 and 2 be coherent?

Neo classical economics is thus challenged with a dilemma: either eschew ordinal utility, or jettison indifference curves. ${ }^{8}$ Cardinal utility and indifference curves go together; you can't have one without the other. Instead, the challenge taken up by mainstream economists is to find some way of squaring this particular circle with ever more sophisticated quantitative techniques at higher levels of abstraction.

The history of the nature of utility has been a checkered one of moving backwards and forwards between cardinalism and ordinalism. Of the three founders of the law of declining marginal utility, Jevons (1871) was probably the most explicit in defining utility in hedonistic terms that could later be made amenable to quantitative techniques of differentiation. Walras (1874), whose project was to derive a pure quantitative approach to the theory of value, deferred to a numeraire from which cardinal utility could be inferred. Walras essentially turned the problem into an objective function by asking the question: based on a given state of endowments, what should the exchange values be in order to ensure the continuation of current production by avoiding any income distribution effects - his "theorem of equivalent redistributions"? Only Menger (1871) remained true to an ordinal conception of the problem, arguing that quantitative techniques alone could never solve the problem posed by the interposition of subjective individuals amongst their objects of choice. Walras essentially cut out the subjective individual from his equations.

The supposed acceptance of ordinalism by modern neoclassical economists could never quite rid itself of the implicit cardinal use made of utility functions or attempts by Lange (1934) and von Neumann and Morgenstern (1944) to cardinalise ordinal utility for interpersonal utility comparisons. Cardinalisation is essential for the application of quantitative methods.

At higher levels of abstraction it is argued that the indexes of ordinal utility can be cardinalised. Lange (1934) tried to do this first by obtaining preferences not only of consumer bundles, but also of the movements between bundles. Lange initiated a series of discussions on the determinateness of the utility function. He tried to prove that from two postulates the measurability of utility is guaranteed: (1) given any two combinations of consumer's goods, the consumer is able to state that one is preferred to the other or equally preferred and (2) given any four combinations of consumers' goods, the individual is always able to place the movements in ordinal relationship. Lange's weakness was his assumption of linear transformation involving scale and origin constants. However, he was later to be proved wrong by Samuelson (1938). ${ }^{9}$

Later the Neumann-Morgenstern cardinal utility for interpersonal utility comparisons used in game theory was derived by the application of probability theory and the accounting of risk preferences. Willingness to pay for lottery tickets with different probabilities of different bundles containing an individual's preferences are used to derive a cardinal measure of utility. Arrow (1950) finally demonstrated all such measures as problematic for welfare economics and the field has been in disarray ever since [49].

The mainstream of the economics profession plays lips service to the fact that utility is ordinal, but by means of indexing implicitly adopts cardinal utility in its application to theory. For example, indices of utility are derived from prices on the basis that MU1/MU2 $=\mathrm{P} 1 / \mathrm{P} 2$. It is then maintained that a higher derived utility is merely expressive of a higher ranking, as opposed to adopting 1st, 2nd, etc for the marginal utilities (MUs). But if this were true, then MU1/MU2 =20/15 is 'ordinally' equivalent to $\mathrm{MU1} / \mathrm{MU} 2=18 / 15$; but both ratios cannot be equated with a single cardinal ratio for P1/P2.

However one tries to resolve the matter, one is always left with the impression of trying to square the circle between utility and price. After all, isn't utility the basis of price? Therefore must there not be a way from the one to the other that proves reconcilable? The positing of such questions is 
logical enough, but they are not rhetorical! They are not rhetorical because the two sides of the equation are incommensurate with one another. - This holds true not only logically because of the impossibility of performing mathematical operations upon ordinal rankings relative to cardinal measures as argued above. It also obtains more fundamentally because, whereas the right-hand side of the equation refers to objects (of price), the left-hand side refers to an individual subject (who is doing the preference ranking). How else can such a ranking be constituted? Ordinality implies judgment and judgment requires a subject to make such judgments. In the market context, there is no representative individual doing a ranking on the basis of some consensus standard of ordering. ${ }^{10}$ Thus judgment and ordinality is inherently a subjective phenomenon. ${ }^{11}$

One possible approach to reconciling the two sides is by viewing the left hand side as related to goods as on the right hand side. But in that case, if we are to eschew all notions of 'intrinsic' value of objects as independent of their evaluators, viz, their subjective users, we are back at cardinal utility with the need for some form of interpersonal utility comparison in order to perform the necessary aggregations for the purposes of deriving their marginal value - at the margin of the aggregate for the particular goods in question. Such an approach turns the reconciliation into a superficial one (or one of convenience for the application of quantitative methods) that eschews subjectivism by embracing the 'intrinsic' value concept as the basis for quantitative theories through the back door. The variety and uniqueness of individual preferences are suppressed by the representative agent and invariant preference constructs are underpinning mainstream models. In reality, the values of individual goods are not independent of the act of valuation of their evaluators. ${ }^{12}$ Prices do not represent any form of measure pertaining to the goods in question, but are rather expressions of valuation that convey useful information about current and planned (anticipated) arrangements of goods for economic action. Seen in this light, neoclassical indifference curve analysis is a pure (and unwarranted) reductionism of price to utility and from object to (an ideal) subject.

\section{Subjectivism}

Attempts at quantification have led to the analysis being increasingly focussed upon the objects, withdrawing attention ever further away from the subjective element that constitutes the basis of price formation. The cost of such withdrawal is the necessity of restrictive assumptions that turn against reality (such as transitivity ${ }^{13}$ and invariance with respect to time, which are all bound up with the problem of judgment and choice in the first place), thereby turning price theory increasingly into an empirical "science" devoid of subjective content.

Such content, however, becomes vital to the ability of prices to transmit information in the market context; to realise that prices are expressions of individual wants in relation to availability. To ignore the subjective basis of price theory is to fail to appreciate the informational surrogate role of prices. It not only provides knowledge about the relative scarcity of goods in meeting individual wants (utilities), but also information that affects individual preferences. It does so in a way that can never be regarded as "given" in any of the senses that it has conventionally become necessary to "fix" before being able to apply indifference curve analysis to it.

So whereas the quantitative theorist can agree that utility is ordinal, he simply evades the problem of aggregation, having attempted to transform its necessarily subjective basis into an objective one. His indifference curves are then based on empirical data sets, which render them sterile or of only historical interest. If the neoclassical economist intends to apply this technique generally - which he most certainly does- he can only do so predicated on arbitrary restrictive assumptions. He goes too far when, knowing that marginal utility must form the basis of price formation, he forgets all about his 
restrictive assumptions and tries to apply his indifference curves to marginal utility considerations ${ }^{14}$, for example, when trying to justify the higher value of a dollar to a poor person relative to a rich person.

\section{Conclusion}

No reconciliation is possible between Austrian and mainstream economists on this matter because of the limitations of the quantitative method which can only deal with the objective phenomena surrounding the subjects that dispose over them (through ownership and control). The quantitative neoclassical theorist necessarily eschews a subjectivist approach to the problem. He nonetheless hangs onto the only notion of subjectivity which he believes can be integrated into a pure quantitative theory or provides it with an interface: the notion of indifference. For if one can be indifferent between two things, does that not necessarily imply a measure of equality? But given the nature of ordinal choice and its relation to the subject (not merely a relation of measure between objects), this theory can say very little about the objects that fall on either side of the indifference map of individual choice. This is because of the arbitrary restrictive assumptions upon which such reasoning (explicitly or implicitly) must rest. The measure of equality is accidental (in the sense that it is place and time bound). It lacks general applicability because of the arbitrary assumption of having to maintain a static state of welfare that can be traced back to Walras' theorem of equivalent redistributions. Such a condition does indeed provide an objective solution to the problem; if only it could be made to stick in the real world.

\section{References}

1. Arrow, K.J. 1950. "A difficulty in the Concept of Social Welfare". Journal of Political Economy, 58. Chicago: University of Chicago Press.

2. Barnett II, W. 1989. "Subjective Cost Revisited," Review of Austrian Economics, Vol. 3, pp. 137-138.

3. Barnett, W. II. 2003. "The Modern Theory of Consumer Behavior: Ordinal or Cardinal?" The Quarterly Journal of Austrian Economics. 6 (1): 41 - 65; http://www.qjae.org/journals/qjae/pdf/qjae6_1_3.pdf.

4. Barnett, W. II and Block W. 2008. "Singularism: Human Action is Binary." Research in the History of Economic Thought \& Methodology. Vol. 26-A, pp. 15-30.

5. Barnett, W. II and Block W. Unpublished. "Thymology, praxeology, demand curves, Giffen goods, diminishing marginal utility and indifference".

6. Baumol, W. 1958. "The cardinal utility that is ordinal." Economic Journal

7. Block, W. 1988. "Comment on Leland Yeager on Subjectivism," Review of Austrian Economics, Vol. II, pp 199-208; http://www.mises.org/journals/rae/pdf/r2_12.pdf.

8. Block, W. 1999. "Austrian Theorizing, Recalling the Foundations: Reply to Caplan," Quarterly Journal of Austrian Economics, Vol. 2, No. 4, winter, pp. 21-39; http://www.mises.org/journals/qjae/pdf/qjae2_4_2.pdf; http://www.mises.org/journals/qjae/pdf/qjae2_4_9.pdf.

9. Block, W. 2003. "Realism: Austrian vs. Neoclassical Economics, Reply to Caplan," Quarterly Journal of Austrian Economics, Vol. 6, No. 3, Fall, pp. 63-76; http://www.mises.org/journals/qjae/pdf/qjae6_3_4.pdf.

10. Block, W. 2005. "Rejoinder to Caplan on Bayesian Economics," Journal of Libertarian Studies. Vol. 19, No. 1, Winter, pp. 79-95; http://blog.mises.org/blog/archives/003654.asp.

11. Block, W. 2007. "Reply to Caplan on Austrian Economic Methodology," Corporate Ownership \& Control, Vol. 4, No. 2, November, pp. 312-zz. 
http://www.virtusinterpress.org/additional_files/journ_coc/issues/COC_(Volume_4_Issue_3_Sp ring_2007_Continued2).pdf.

12. Block, W. and Barnett II W. 2012. "Transitivity and the money pump." Quarterly Journal of Austrian Economics vol. 15, no. 2. Summer, pp. 237-251;

http://mises.org/journals/qjae/pdf/qjae15_2_5.pdf.

13. Buchanan, J. M. and Thirlby G.F. 1981. L.S.E. Essays on Cost, New York: New York University Press.

14. Buchanan, J. M. 1969. Cost and Choice: An Inquiry into Economic Theory, Chicago: Markham.

15. Buchanan, J. M. 1979. "The General Implications of Subjectivism in Economics," in What Should Economists Do?, Indianapolis: Liberty Press

16. Butos, W. and Koppl R. 1997. "The varieties of subjectivism: Keynes, Hayek on expectations." History of Political Economy, 29 (2), pp. 327-59.

17. Caplan, B.. 1999. "The Austrian Search for Realistic Foundations," Southern Economic Journal, April, Vol. 65, No. 4, pp. 823-838.

18. Caplan, B., 2000. "Probability, Common Sense, and Realism: A Reply to Hulsmann and Block," Quarterly Journal of Austrian Economics, Vol. 4, No. 2, Summer, pp. 69-86; http://www.mises.org/journals/qjae/pdf/qjae4_2_6.pdf.

19. Caplan, B.. 2001. "Probability, Common Sense, and Realism: A Reply to Huelsmann and Block," Quarterly Journal of Austrian Economics; Vol. 2, No. 4, summer, pp. 69-86; http://www.mises.org/journals/qjae/pdf/qjae4_2_6.pdf.

20. Caplan, B. 2003. "Probability and the Synthetic $A$ Priori: A Reply to Block." Quarterly Journal of Austrian Economics; Vol. 6, No. 3, Fall, pp. 77-83;

http://www.mises.org/journals/qjae/pdf/qjae6_3_5.pdf.

21. Caplan, B. 2008. "The Trojan Horse Example" June 16; http://econlog.econlib.org/archives/2008/06/the trojan_hors.html.

22. Callahan, G. 2003. "Choice and Preference," February 10; http://mises.org/story/1163.

23. Carilli, A. M. and Dempster, G. M. 2003. "A note on the treatment of uncertainty in economics and finance," Journal of Education for Business 79.2 Nov. 1, pp. 99-103.

24. Cordato, R. E. 1989. "Subjective Value, Time Passage, and the Economics of Harmful Effects," Hamline Law Review, Vol. 12, No. 2, Spring, pp.229-244.

25. DiLorenzo, T. J. 1990. "The Subjectivist Roots of James Buchanan's Economics," The Review of Austrian Economics, Vol. 4, pp. 180-195.

26. Ekelund, R. B., Jr., and Tollison R.D. 1991. Economics. $3^{\text {rd }}$. HarperCollins Publishers; p. 148150.

27. Garrison, R. 1985. "A Subjectivist Theory of a Capital Using Economy," in O'Driscoll, Gerald P. and Rizzo, Mario, The Economics of Time and Ignorance, Oxford: Basil Blackwell.

28. Gordon, D. 1993. Book review of Welfare Economics and Externalities in an Open-Ended Universe: A Modern Austrian Perspective by Roy E. Cordato. Boston: Kluwer Academic Publishers, 1992; The Review of Austrian Economics Vol. 6, No. 2: 99-112; http://www.mises.org/journals/rae/pdf/RAE6_2_4.pdf.

29. Gunning, J. P. 1990. The New Subjectivist Revolution: An Elucidation and Extension of Ludwig von Mises's Contribution to Economic Theory, Savage, MD: Rowan and Littlefield.

30. Hayek, F. A. 1979. The Counter-Revolution of Science, $2^{\text {nd }}$ ed. Indianapolis, IN: LibertyPress

31. Hicks, J. R. 1946 [1939]. Value and Capital: An Inquiry into Some Fundamental Principles of Economic Theory. Oxford: Clarendon Press, second ed.

32. Hoppe, H.H. 2005. "Must Austrians Embrace Indifference?," Quarterly Journal of Austrian Economics, Vol. 8, No. 4, Winter, pp. 87-91; 
http://www.mises.org/journals/qjae/pdf/qjae8_4_6.pdf.

33. Hoppe, H.H. 2007. "The limits of numerical probability: Frank H. Knight and Ludwig von Mises and the frequency interpretation." The Quarterly Journal of Austrian Economics, vol. 10, no. 1, spring: 3-21; http://mises.org/journals/qjae/pdf/qjae10_1_1.pdf.

34. Hülsmann, J. G. 1999. "Economic Science and Neoclassicism." Quarterly Journal of Austrian Economics, Vol. 2 Num. 4, pp. 1-20; http://www.mises.org/journals/qjae/pdf/qjae2 4 1.pdf.

35. Jevons,W.S. 1911 [1871]. The Theory of Political Economy. London: Macmillan and Co. Journal of Happiness Studies; http://www.springer.com/social+sciences/quality+of+life+research/journal/10902.

36. Jung, C. G. 1971 [1921]. Psychological Types. Bollingen Series XX, volume 6, Princeton University Press.

37. Kirzner, I. M. 1973. Competition and Entrepreneurship, Chicago: University of Chicago Press.

38. Kirzner, I., ed. 1986. Subjectivism, Intelligibility and Economic Understanding, New York: New York University Press.

39. Lange, O., R. 1934. "The Determinateness of the Utility Function". Review of Economic Studies. June 1934 pp. 218-25. "A note on the Determinateness of the Utility Function". Review of Economic Studies. February 1935 pp. 155-8. "Notes on the Determinateness of the Utility Function". By Phelps Brown, Bernadelli and Lange. Review of Economic Studies. October 1937 pp. 66-77.

40. Machaj, M.. 2007. "A Praxeological Case for Homogeneity and Indifference." New Perspectives on Political Economy, Vol. 3, No. 2, pp. 231 - 238; http://pcpe.libinst.cz/nppe/3_2/nppe3_2_5.pdf.

41. Menger, C. 1950[1871]. Principles of Economics. Editors and translators, James Dingwall and Bert F. Hoselitz, Glencoe, IL: Free Press.

42. Mises, L. von. [1949] 1998. Human Action, Scholars' Edition. Auburn: Mises Institute.

43. Murphy, R. P. 2008. “Austrian Realists.” July 17; http://mises.org/story/3028.

44. Murphy, R. P., Robert Wutscher and Walter E. Block. 2010. "Mathematics in Economics: An Austrian Methodological Critique." Philosophical Investigations, January, Vol. 33, No. 1, pp. 44-66; http://www3.interscience.wiley.com/cgi-bin/fulltext/123209256/PDFSTART; http://onlinelibrary.wiley.com/doi/10.1111/j.1467-9205.2009.01397.x/full.

45. von Neumann, J and Morgenstern, O. 1944. The Theory of Games and Economic Behavior. Princeton University Press.

46. Pigou, A. C. 1932. The Economics of Welfare .4th ed., London: Macmillan.

47. Rizzo, M. J. 1979. "Uncertainty, Subjectivity, and the Economic Analysis of Law", in Mario J. Rizzo (ed.), Time, Uncertainty, and Disequilibrium, Lexington, MA: Lexington Books, pp. 7190.

48. Rizzo, M. J. 1980. "The Mirage of Efficiency," Hofstra Law Review, Vol. 8, pp. 641-658.

49. Ross, D. 1999. What People Want: The concept of Utility from Bentham to Game Theory. University of Cape Town Press.

50. Rothbard, M. N. 1979. "Comment: The Myth of Efficiency," in Mario J. Rizzo (ed.), Time, Uncertainty, and Disequilibrium, Lexington, MA: Lexington Books: pp. 91-96.

51. Rothbard, M. N. 1993. Man, Economy, and State, 2 vols., Auburn, AL: Ludwig von Mises Institute.

52. Rothbard, M. N. 1997. "Toward a Reconstruction of Utility and Welfare Economics," in The Logic of Action: Method, Money and the Austrian School, Vol. I, Cheltenham, UK: Edward Elgar, pp. 211-254. 
53. Samuelson, P. 1938. "The Numerical Representation of Ordered Classifications and the Concept of Utility". The Review of Economic Studies, 1. Oxford: Blackwell Publishers.

54. Stigler, G. J. 1950. "The Development of Utility Theory," Journal of Political Economy; Vol. 58, No. 5, October, pp. 373-396.

55. Stringham, E. 2001. "Kaldor-Hicks Efficiency and the Problem of Central Planning," Quarterly Journal of Austrian Economics, Vol. 4, No. 2 (Summer) 41-50; http://www.mises.org/journals/qjae/pdf/qjae4_2_3.pdf.

56. Stringham, E. 2008. "Economic Value and Cost Are Subjective," in The Handbook of Austrian Economics, Peter Boettke (editor), Cheltenham, UK: Edward Elgar Publishing; http://mises.org/journals/scholar/stringham4.pdf.

57. Stringham, E., and White, Mark. 2004. "Economic Analysis of Tort Law: Austrian and Kantian Perspectives," in Law and Economics: Alternative Economic Approaches to Legal and Regulatory Issues, Margaret Oppenheimer and Nicholas Mercuro (editors) New York: M.E. Sharpe, 374-92. http://www.sjsu.edu/stringham/docs/Stringham.and.White2005.pdf.

58. Walras, L. 1954 [1874]. Elements of Pure Economics: Or the theory of social wealth. 1954 translation of 1926 edition. Homewood Ill: Richard Irwin.

Notes

1. Such rank orderings were utilized by Menger (1950), Rothbard (1993). For the claim that they are incompatible with the Misesian (1998) notion of singularism, see Barnett and Block (2008).

2. Note that indifference is implied by cardinal, but not ordinal utility. Or, at the least, cardinal utility is logically compatible with indifference (two goods, or combinations thereof, as on an indifference curve, yield an equal amount of cardinal utility, and we are thus indifferent between the two of them). In the latter case, there is only preference, not indifference; in the former, Jones is indifferent between one shirt, or two watches, or four pencils. For a defense of indifference, see Caplan, 1999, 2000, 2001, 2003, 2008. For a critique: Block, 1999, 2003, 2005, 2007; Callahan, 2003; Carilli and Dempster, 2003; Hoppe, 2005, 2007; Hulsmann, 1999, Machaj, 2007; Murphy, 2008; Stringham, 2001, 2008; Stringham and White, 2004. More generally, see Murphy, Wutscher and Block, 2010.

3. This applies, even, to those who specialize in "happiness studies." See for example Journal of Happiness Studies. Nowhere in this literature can be found a claim to the effect that happiness itself, or utility per se rose or fell by $2.3 \%$ or by any other such cardinal number. Rather, utility is operationally defined as an amalgamation of answers to questions on the part of specific people at certain times and places, and, as the numbers that result from these surveys are indeed cardinal, it is entirely legitimate to say that satisfaction rose or fell by a certain percentage between any two given surveys, either at different times or places or both.

4. Cited in Gordon, 1993.

5. Utils also appear on the vertical axis on numerous occasions in the economics literature. These are clearly "smoking gun" instances of the fallacious employment of cardinal, not ordinal utility in the mainstream economics literature. See on this Barnett (2003) who mentions several such cases.

6. This phrase is somewhat unsettling, given practices in academia and elsewhere with regard to "correctness."

7. There is of course a sense in which a number ending in a "th" can be and indeed is a legitimate cardinal number, not an ordinal one. For instance, the number 1/18, and pronounced "one eighteenth" is a perfectly acceptable number in mathematics. But it is cardinal, not ordinal.

8. We have no objection to the concept of "indifference" itself. This word is a perfectly acceptable one in the English language. Everyone knows precisely what it means. The present authors, too, are accustomed to employing it. Our objection arises with its use as a matter of economic science. An analogy may make this clear. In physics, "work" equals force time distance. But if even a top athlete holds bar bells of pretty much any weight, even as little as five pounds at arm's distance, he will soon tire. Will he be doing any "work?" Not in the technical sense of physics. But in ordinary language, as we see the sweat on his brow from this exercise, all would agree with the claim that he is working very hard indeed. It is the same with "indifference." Unobjectionable in ordinary language, but not in the technical language of economics. 
9. Lange's theorem rested on the critical assumption that agents' ordinal utility functions are linear under the transformation to preferences over readjustments. Samuelson showed that there is no a priori reason to assume why an individual's preference scale should obey such an arbitrary restriction.

10. Not only do individuals rank things differently and in incompatible ways, but some do not rank at all (at least not in the rational sense) according to some. For example Jung (1971) classifies individuals into four broad functional categories, arguing that for any individual to function coherently in the world he has to develop one of them as his superior function to which the other functions become subordinate (separately as inferior and auxiliary functions) whenever a conflict in the rankings in the context of human action arises. Thus there are the rational types, who are either differentiated thinking or feeling individuals whose value rankings are predicated upon one or the other of these two functions, generally suppressing the other whenever a conflict arises. In contrast; there are the nonrational, but perceptive types, the sensation and intuitive individuals, whose value systems are not based on rankings per se, but upon the intensity of their experiences, seeming wholly irrational to the rational types (but that may nonetheless use one of the rational functions as an auxiliary function in order to communicate coherently with others). This analysis is in sharp contrast to the Austrian view of rationality as purposefulness (see on this Mises, 1998 and Kirzner, 1973.)

11. States Hayek $(1979,52)$ : "And it is probably no exaggeration to say that every important advance in economic theory during the last hundred years was a further step in the consistent application of subjectivism." Also, see the following on this issue: Barnett, 1989; Block, 1988; Buchanan and Thirlby, 1981; Buchanan, 1969, 1979; Butos and Koppl, 1997; Cordato, 1989; DiLorenzo, 1990; Garrison, 1985; Gunning, 1990; Kirzner, 1986; Mises, 1998; Rizzo, 1979, 1980; Rothbard, 1979, 1997; Stringham, 2008.

12. Without using it as analogy, this conclusion has an uncanny resonance with the implications of wave-particle theory of quantum physics, where the act of observation is seen to influence the results of experiments.

13. For a critique of this concept from an Austrian point of view, see Block and Barnett, 2012

14. As opposed to simple - but admittedly more sterile - marginal rates of substitution analyses

\section{Diagram 1}

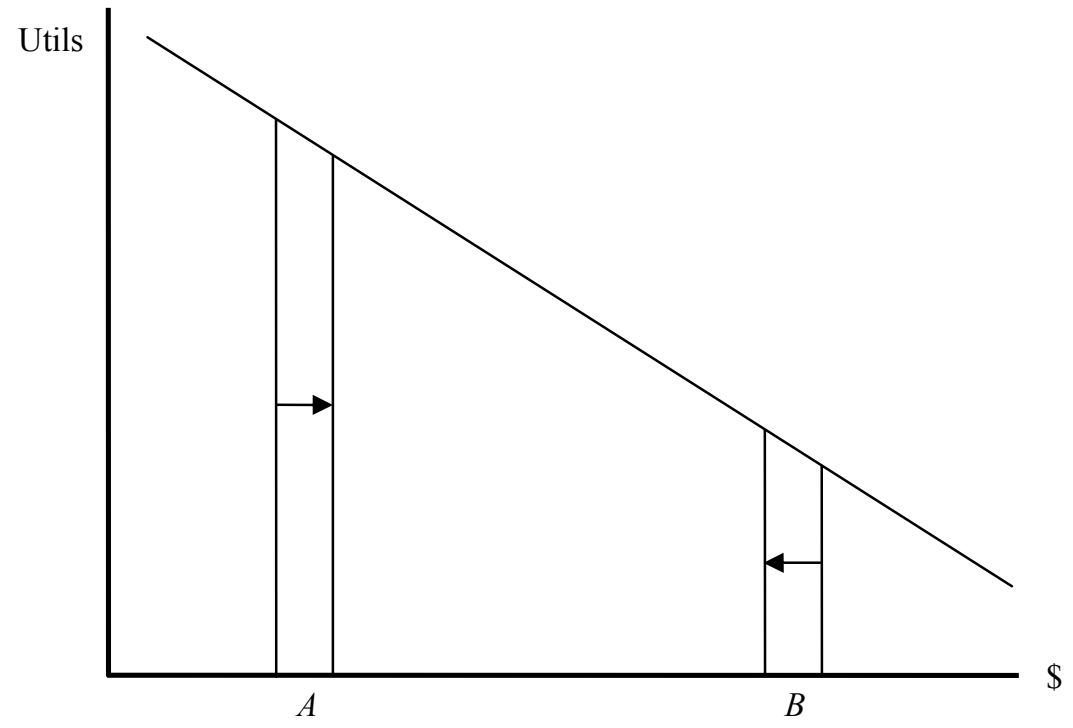


Diagram 2

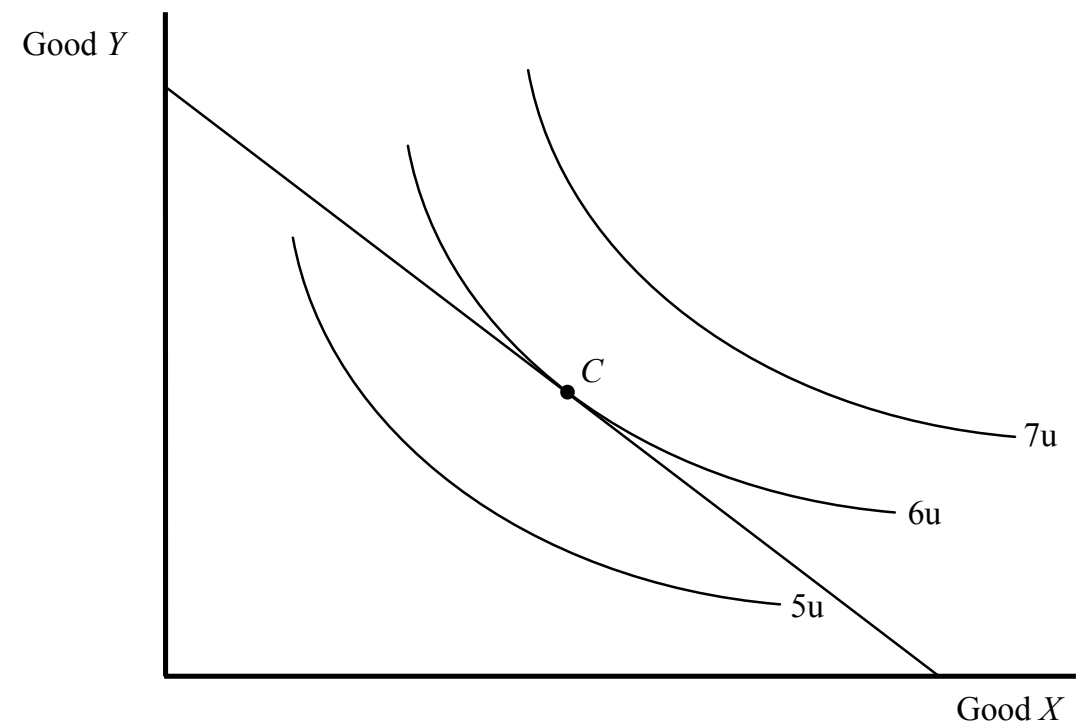

